\title{
Anterolateral Ligament Tear in Acute Anterior Cruciate Ligament Rupture: Diagnostic Accuracy of MRI
}

\author{
ABDELMONEM M. MOURAD, M.D. \\ The Department of Radiodiagnosis, Saudi German Hospital, Riyadh, Saudi Arabia and The Department of Radiology, \\ Faculty of Medicine, Assiut University, Egypt
}

\begin{abstract}
Background: The anterolateral ligament is a special ligamentous structure traversing the knee joint along its anterolateral part, originating from the lateral femoral epicondyle, with an oblique course through the joint capsule to be inserted at the anterolateral tibial surface just posterior to Gerdy's tubercle. Evaluation of anterolateral ligament has been done by MRI. The rate of its visualization is by MRI is varying from 50 to $100 \%$. There is a significant increase in the incidence of association between the anterolateral ligament and ACL lesions as detected by MRI.
\end{abstract}

Aim of Study: The present study was aimed to give a comprehensive evaluatation for the ability of MRI to diagnose anterolateral ligaments injuries in patients with acute tears of the anterior cruciate ligaments.

Material and Methods: A retrospective study on ninety six patients underwent ACL reconstruction was done. The MRI knee studies of those patients were done within two months after the initial injury and the anterolateral ligament pattern was evaluated; either non-detectable, normal or pathological. Two expert musculoskeletal radiologists evaluated the images.

Results: The present study revealed that $20(21 \%)$ cases of the 96 ACL injured cases, Anterolateral Ligament (ALL) could not be detected $(21 \%)$, while $76(79 \%)$ could be detected with MRIs. Twenty cases of the visualized ALLs were seen intact $(26 \%)$, on the other hand, 56 knees $(74 \%)$ showed imaging abnormalities. The site of injury of the ALL was involving mainly the distal segment (tibial part) in 34 cases (61\%), the proximal segment (femoral part) was less common in 14 cases $(25 \%)$ and both parts were injured in 8 cases $(14 \%)$.

Conclusion: Anterolateral Ligament (ALL) are commonly associated with acutely ruptured Anterior Cruciate Ligament (ACL). Therefore, MRI findings together with clinical correlations are still essential factors in the surgical decision reconstruction of ALL avoiding unsatisfactory results post ACL reconstruction alone.

Correspondence to: Dr. Abdelmonem M. Mourad, The Department of Radiodiagnosis, Saudi German Hospital, Riyadh, Saudi Arabia and The Department of Radiology, Faculty of Medicine, Assiut University, Egypt
Key Words: Anterolateral ligament - Anterior cruciate ligament-Magnetic resonance imaging.

\section{Introduction}

LONG time ago, it was assumed that anterolateral instability is caused by tearing of the middle third of the anterolateral capsule and may be accentuated by a rupture of ACL [1]. Additionally, the anterolateral capsule is a discrete ligament called the Anterolateral Ligament (ALL) [2-6]. The anterolateral ligament is a special ligamentous structure traversing the knee joint along its anterolateral part, originating from the lateral femoral epicondyle, with an oblique course through the joint capsule showing adherent attachment to the lateral meniscus and lastly to be inserted at the anterolateral tibial surface just posterior to Gerdy's tubercle [3]. It has an important impact on the internal rotation stability of the knee mainly between 30 and 90 degrees of knee flexion $[3,6,7]$. Therefore, biomechanical researches documented that injury of the ALL affects significantly the pivot shift $[8,9]$. So, the clinical pathways toward high-grade pivot shift patients with ACL injuries has been changed [10]. This potential role in knee kinematics raised the need for its repair with ACL reconstruction) [11-13]. The main reasons for complete ACL tears are mainly due to twisting, non contact injuries, with a pivot like mechanism consisting of combination between knee abduction and tibial internal rotation [14,15]. Evaluation of the injured ALL has been done by MRI and in some studies, the rate of its visualization is varying from 50 to $100 \%$ [2,16]. Claes et al., [17] confirmed that the increased incidence of association between the ALL and ACL

\section{Abbreviations:}

ALL : Anterolateral Ligament.

ACL : Anterior Cruciate Ligament.

MRI : Magnetic Resonance Imaging. 
lesions in $80 \%$ and the ALL could not be visualized in nearly $25 \%$ of the patients.

Aim of the work: Our study was aimed to identify the pre-operative conditions of the Anterolateral Ligament (ALL) and assess its frequency of injury in association with acute Anterior Cruciate Ligament (ACL) tear by MRI.

\section{Material and Methods}

Patients: A retrospective study on 96 male patients, their ages ranged from 18 to 50 years old with mean age 29 years. All samples had surgically reconstructed anterior cruciate ligaments with preoperative MRI of the knee that had been carried out in the Radiology Department of Saudi German Hospital Riyadh, K.S.A. in the period from January 2017 till March 2018. The hospital institutional review boards approved this study. patients consents were not required.

Inclusion criteria: Patients proved surgically to have ACL injury for whom MRI studies were carried out within 2 months after the incidence of the trauma.

Exclusion criteria: Patients with bad MRI images quality, patients with severe osteoarthritis, patients with a previous knee surgery and those with previous knee infection.

MRI technique: The MRI studies were done on 1.5-T system (Magnetom Symphony, Siemens, Germany) using a phased array 8 channel Knee coil. The knee should be held in approximately $15^{\circ}$ of flexion with neutral rotation.

Imaging parameters: Axial and coronal T2 weighted Fat-Saturated (FS) (TR/TE3000/28, slice thickness 3mm, FOV:160mm, matrix size $307 \mathrm{X}$ 384), coronal T1 weighted (TR/TE500/14, slice thickness 3mm, FOV:150mm, matrix size $307 \mathrm{X}$ 384), sagittal PD (TR/TE3500/50, slice thickness $3 \mathrm{~mm}$, FOV: $160 \mathrm{~mm}$, matrix size 307 X 384), sagittal T2 weighted Fat-Saturated (FS) (TR/TE: 3500/ 40, slice thickness $3 \mathrm{~mm}$, FOV: $160 \mathrm{~mm}$, matrix size 307 X 384).

Data analysis: Two musculoskeletal radiologists of more than 5 years experience evaluated the images, the ALL was considered visualized "when fibers of hypo signal intensity were detected extending from the distal femur, lateral epicondyle area, obliquely into the anterolateral border of the proximal part of the tibia. The ALL was considered abnormal in case of a complete ligamentous tear, irregular contour, peri or intra ligamentous edema or a combination of those MRI criteria was noted.
The injuries of ALL were categorized according to the site of the injury into two parts: Proximal (the tear was noted in the part extended from femoral epicondyle to the meniscofemoral segment) and distal (from the level of the body of the meniscus to the tibial insertion). The ALL was categorized as non visualized or visualized and the visualized group was categorized into normal or abnormal ALL.

Statistical analysis: All cases were categorized as per the condition of ALL, the sites of injuries, as well as their frequencies, were listed in tables. Moreover, the 95\% Confideance Interval (CI) has been calculated using SPSS package Version 25.

\section{Results}

In 20 cases ALL could not be detected (21\%), while could be detected in the remaining 76 MRIs (79\%). Twenty of the visualized ALLs were seen intact (26\%) Fig. (2), on the other hand 56 knees (74\%) showed imaging abnormalities. The site of injury of the ALL was mainly at the distal segment (tibial part) in 34 cases (61\%) Fig. (4), the proximal segment (femoral part) was less common in 14 cases $(25 \%)$ and both parts were injured in 8 cases (14\%) Figs. ( 3 \& 6B). Moreover, the $95 \%$ confidance interval and frequency was shown in (Table 1).

Table (1): Location and frequency of the visualized ALL injuries.

\begin{tabular}{lccc}
\hline & No of patients & Frequency & CI \\
\hline Distal (tibial) & 34 & $61 \%$ & $0.477-0.746$ \\
Proximal (femoral) & 14 & $25 \%$ & $0.147-0.390$ \\
Combined & 8 & $14 \%$ & $0.065-0.267$ \\
\hline
\end{tabular}

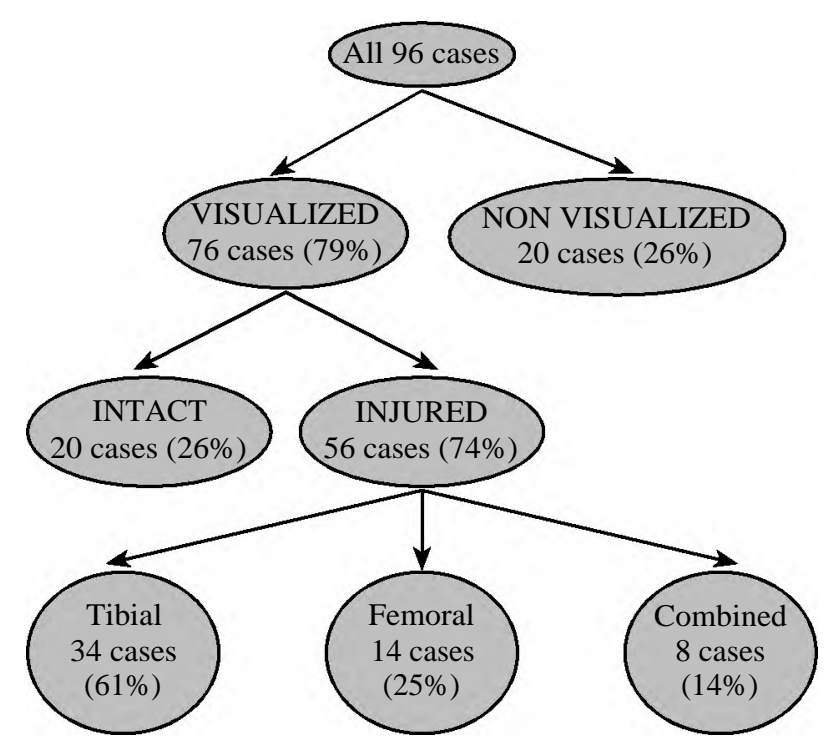

Fig. (1): The reliability of MRI to visualize ALL and diagnose the site injury. 


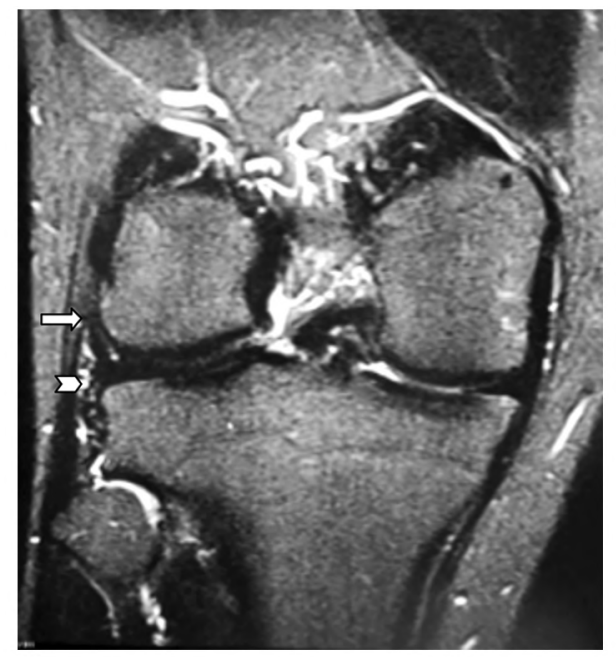

Fig. (2): MRI coronal T2 FS-weighted images showing a normal ALL. Femoral part (arrow) and tibial part (arrow head).

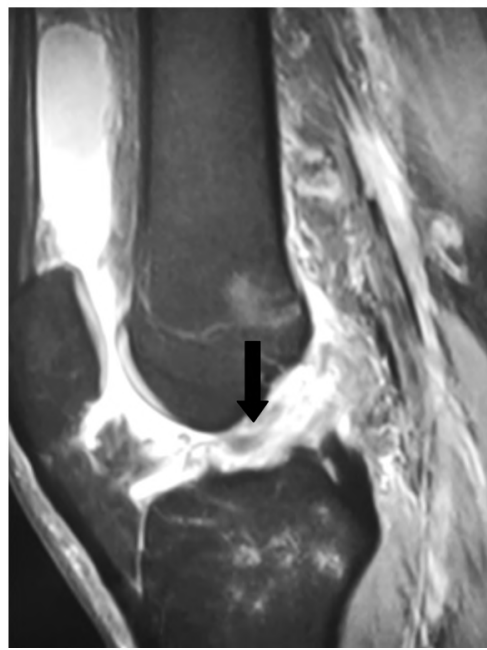

(A)

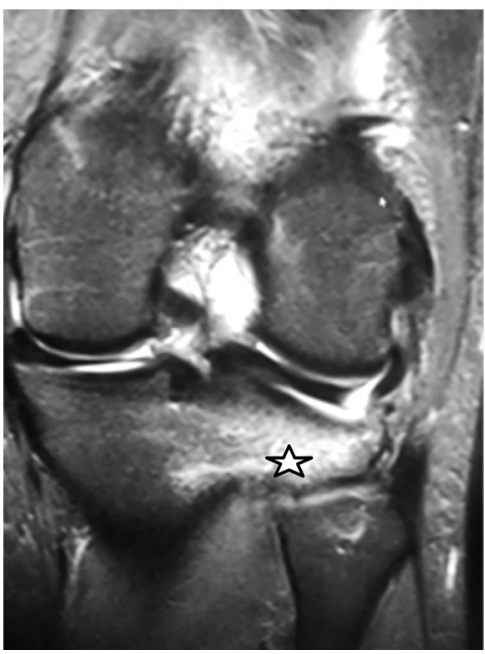

(B)

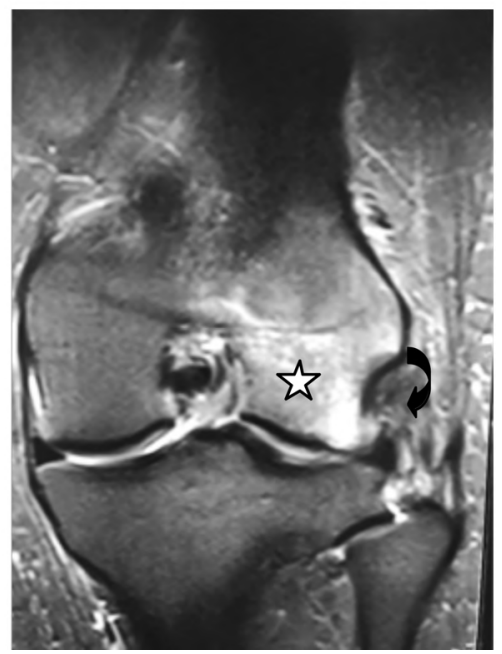

(C)

Fig. (3): (A) MRI sagittal T2 FS-weighted images demonstrating complete rupture of the ACL (black arrow). (B) and (C) Coronal T2 FS representing bone marrow edema of the lateral femoral condyle and lateral tibial plateau (stars) and rupture of the anterolateral ligament (curved black arrow).

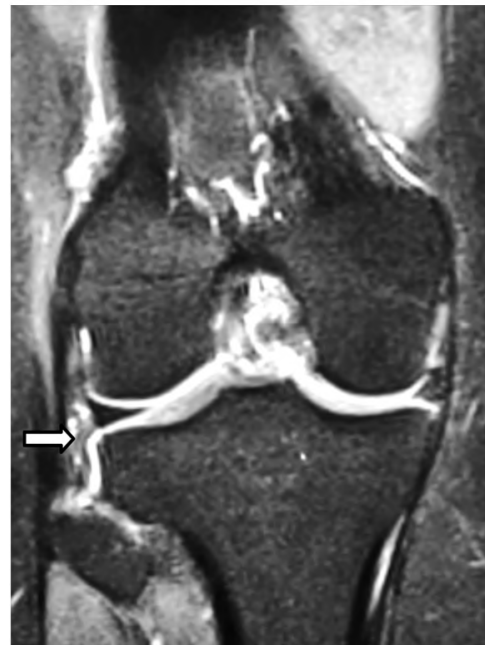

Fig. (4): MRI coronal T2 FS-weighted images showing complete tear of the ALL at its tibial attachment (white arrow).
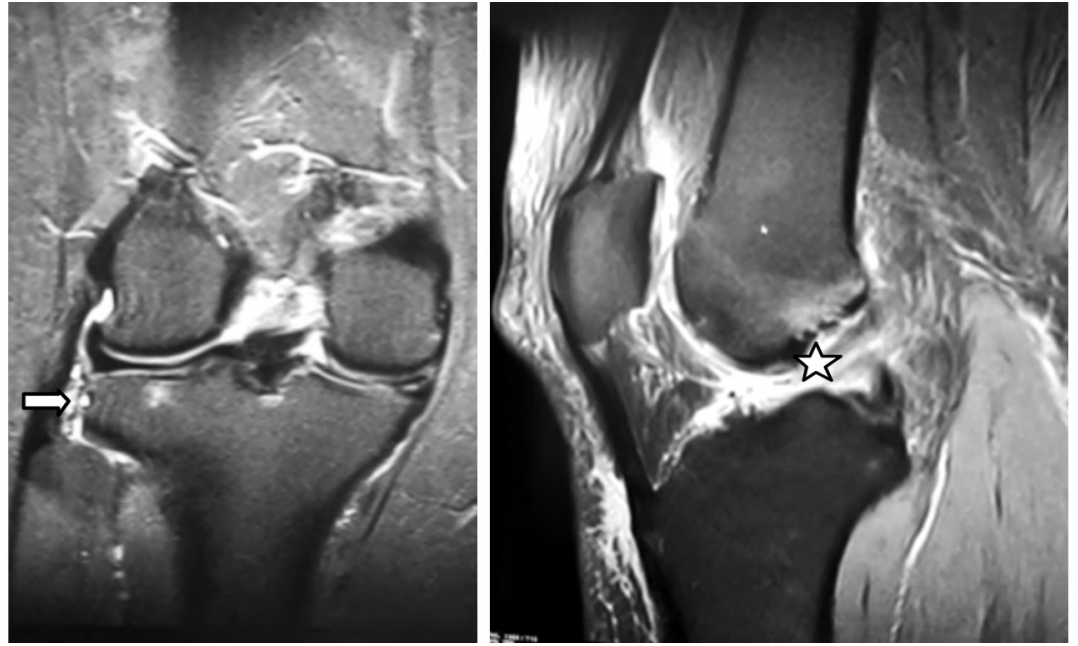

Fig. (5): MRI coronal T2FS-weighted images showing complete tear of the ALL at its tibial attachment (white arrow) in a completely rupture ACL (star). 


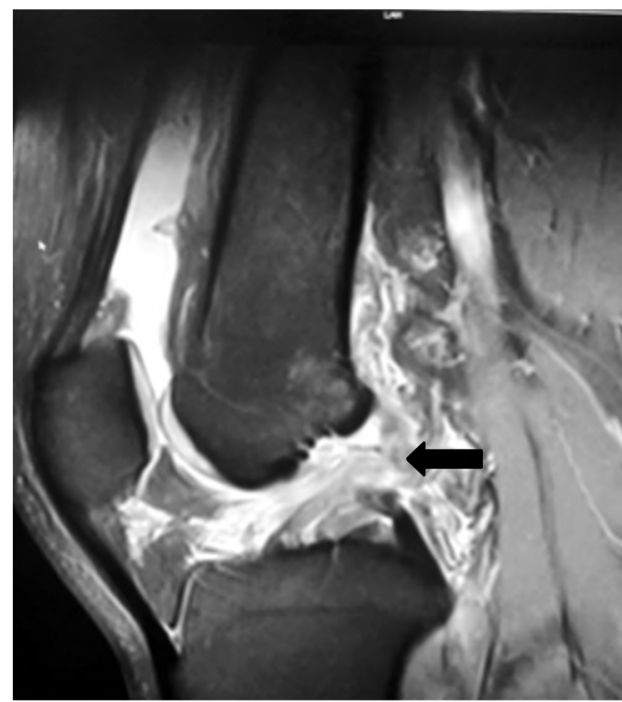

(A)

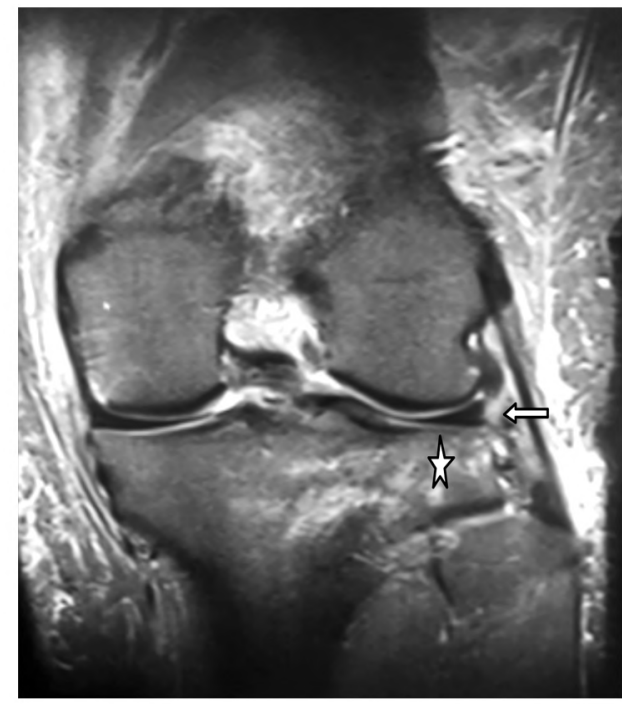

(B)

Fig. (6): (A) MRI sagittal T2 FS-weighted images demonstrating complete rupture of the ACL (black arrow). (B) Coronal T2 FS representing bone marrow edema of the lateral tibial plateau (star) and rupture of the whole segment of anterolateral ligament (white arrow).

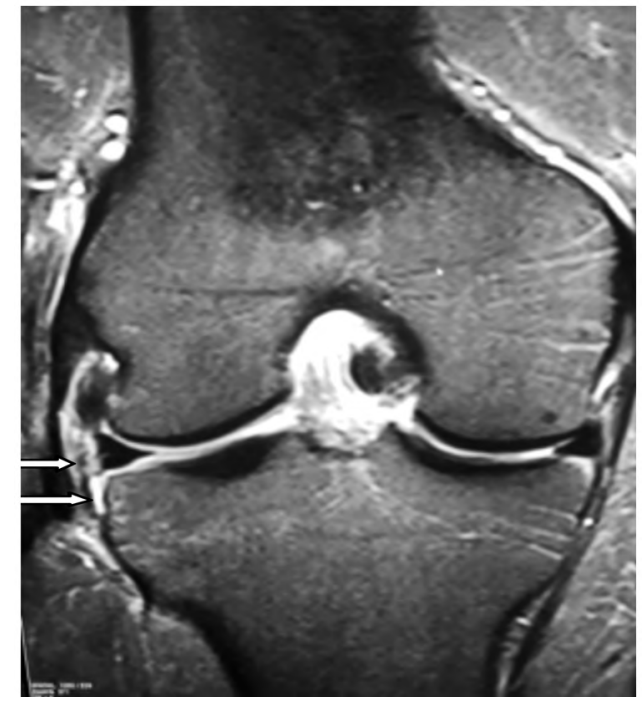

Fig. (7): MRI knee coronal T2 FS-weighted images showing complete tear of the ALL at its femoral and tibial parts (white arrows).

\section{Discussion}

The detection of the Anterolateral Ligament (ALL) gives a high impact for diagnosis and management of the instability of the knee problems resulting from the rotation injuries $[\mathbf{3 , 5 , 1 8 - 2 0 ]}$. Consequently, reconstructive repair of the ALL together with the Anterior Cruciate Ligament (ACL) is improving the surgical and functional outcome [21,22] .

Moreover, the anterolateral location of ALL may interfere with its visualization and accurate assessment by magnetic resonance imaging due to the partial volume effect caused by nearby structures like the capsule, the collateral ligament, the popliteus tendon, and the iliotibial tract. Also its small thickness and anatomical variations are affecting the full length visualization $[23,24]$

Helito et al., stated that ALL is only damaged when the ACL is completely torn, which expose the knee to greater rotational forces, or that its integrity has a protective factor for ACL injury and that the ACL is only fully damaged if its secondary restrictors are affected [25].

In our study, ALL has been identified in 76 MRIs (79\%) with acute ACL injuries that is consistant with Claes et al., as they identified the whole ALL ligament in ACL injured knees in 76\% of 271 patients with high injury rate about $79 \%$ in their study [17]. Moreover, Kosy et al., [13] reported detailed rates of identification of the ALL in 94\% of 100 knees of patients suffering from ACL injury [13]. Helito et al., [23] had a study in 39 patients and could identify ALL in $65 \%$ of the MRI but they added additional sequences of coronal proton density-weighted without fat saturation [23]. Also, Taneja et al., [16] visualized the ALL in $51 \%$ of 70 knees using MRI studies and revealed that complete visualization was in $11 \%$ and partial visualization $40 \%$ [16]

Our results are in agreement with other studies reported that their detection rates ranging between $(70-90 \%)[5,11,17,19,21]$ on the other hand, Porrino 
et al., [26] characterized the ALL in all MRI scans of 53 patients using a $3.0 \mathrm{~T}$ device.

Claes et al., [17] described that ALL injury was found in most of the examined cases, whereas in our study about two thirds of the patients had ALL injuries.

According to our study, the visualization of the injured ALL by MRI in acute ACL injury cases was achieved in 56 of the visualized cases (76\%), this is confirming the common mechanism of injury which comprising the marked internal rotation of the tibia. Additionally, 74\% association of ACL and ALL injuries in our study is matching with Claes et al., [17] who found $79 \%$ association [17].

In our study, the majority of the patients showed distal, tibial, injury in 34 cases $(61 \%)$, the same as Claes et al., who found most of the injuries in the tibial portion [27], this finding can be justified as the origin of the ALL is at lateral femoral epicondyle with ideal flexion-extension axis of the knee, transepicondylar axis, so injury to the ALL commonly occurs at the distal segment [29]. Also our results in agreement with Porrino et al., who stated that the femoral part of the ALL is not commonly seen injured using MRI due to it is intimate relation with origin of the LCL, as the injury detection in our study was less than the tibial part.

\section{Limitations:}

Absence of the gold standard due to inability to identify the ALL by arthroscope due to extra articular location, this might cause positive or negative findings, also no specific MRI protocol for ALL evaluation.

\section{Recommendations:}

Increasing the knowledge of the ALL has stimulated the research to improve the ACL surgical reconstruction results. The long term and further comparative follow-up studies are essential to evaluate the surgical outcome of the ACL after treatment of the ALL. Future studies using smaller slice thickness, less spacing between images, volumetric sequences and special sequences focused on the ALL will enhance the accuracy in the visualization of this structure.

\section{Conclusion:}

ALL injuries are commonly associated with acutely ruptured ACL. According to our results, the simultaneous of ACL and ALL injuries should be considered for the radiologist for interpreting MRI of ACL injured knee. Additionally, MRI findings and clinical correlation are considered essential in the decision of surgical reconstruction of ALL to avoid unsatisfactory results of post ACL reconstruction alone.

\section{References}

1- HUGHSTON J.C., ANDREWS J.R., CROSS M.J. and MOSCHI A.: Classification of knee ligament instabilities. Part II. The lateral compartment. J. Bone Joint Surg. Am., 58 (2): 173-9, 1976.

2- CATERINE S., LITCHFIELD R., JOHNSON M., CHRONIK B. and GETGOOD A.: A cadaveric study of the anterolateral ligament: Re-introducing the lateral capsular ligament. Knee Surg Sports Traumatol Arthrosc, 23 (11): 3186-95, 2015.

3- CLAES S., VEREECKE E., MAES M., VICTOR J., VERDONK P. and BELLEMANS J.: Anatomy of the anterolateral ligament of the knee. J. Anat., 223 (4): 321-8, 2013.

4- DODDS A.L., HALEWOOD C., GUPTE C.M., WILLIAMS A. and AMIS A.A.: The anterolateral ligament: anatomy, length changes and association with the Segond fracture. Bone Joint J., 96-B (3): 325-3 1, 2014.

5- STIJAK L., BUMBASIREVIC M., RADONJIC V., KADIJA M., PUSKAS L., MILOVANOVIC D. and FILIPOVIC B.: Anatomic description of the anterolateral ligament of the knee. Knee Surg Sports Traumatol Arthrosc, 24 (7): 2083-8, 2016.

6- VINCENT J.P., MAGNUSSEN R.A., GEZMEZ F., UGUEN A., JACOBI M., WEPPE F., AL-SAATI M.F., LUSTIG S., DEMEY G., SERVIEN E. and NEYRET P.: The anterolateral ligament of the human knee: An anatomic and histologic study, Knee Surg Sports Traumatol Arthrosc., 20 (1): 147-52, 2012.

7- HELITO C.P., DEMANGE M.K., BONADIO M.B., et al.: Anatomy and histology of the knee anterolateral ligament. Orthop. J. Sports Med., 1: 2325967113513546 , 2013.

8- PARSONS E.M., GEE A.O., SPIEKERMAN C. and CAVANAGH P.R.: The biomechanical function of the anterolateral ligament of the knee. Am. J. Sports Med., 43: 669-74, 2015.

9- VAN DER WATT L., KHAN M., ROTHRAUFF B.B., et al.: The structure and function of the anterolateral ligament of the knee: A systematic review. Arthroscopy, 31: 56982.e3, 2015.

10- DODDS A.L., GUPTE C.M., NEYRET P., WILLIAMS A.M. and AMIS A.A.: Extra-articular techniques in anterior cruciate ligament reconstruction: A literature review. J. Bone Joint Surg. (Br.), 93: 1440-8, 2011.

11- KENNEDY M.I., CLAES S., FUSO F.A., WILLIAMS B.T., GOLDSMITH M.T., TURNBULL T.L., WIJDICKS C.A. and LaPRADE R.F.: The anterolateral ligament: An anatomic, radiographic, and biomechanical analysis. Am. J. Sports Med., 43 (7): 1606-15, 2015.

12- KITTL C., HALEWOOD C., STEPHEN J.M., GUPTE C.M., WEILER A., WILLIAMS A. and AMIS A.A.: Length change patterns in the lateral extra-articular structures of the knee and related reconstructions. Am. J. Sports Med., 43 (2): 354-62, 2015. 
13- KOSY J.D., MANDALIA V.I. and ANASPURE R.: Characterization of the anatomy of the anterolateral ligament of the knee using magnetic resonance imaging. Skelet. Radiol., 44 (11): 1647-53, 2015.

14- BODEN B.P., DEAN G.S., FEAGIN J.A., Jr. and GARRETT W.E. Jr.: Mechanisms of anterior cruciate ligament injury. Orthopedics, 23: 573-8, 2000.

15- OH Y.K., LIPPS D.B., ASHTON-MILLER J.A. and WOJTYS E.M.: What strains the anterior cruciate ligament during a pivot landing? Am. J. Sports Med., 40: 574-83, 2012.

16- TANEJA A.K., MIRANDA F.C., BRAGA C.A., GILL C.M., HARTMANN L.G., SANTOS D.C., ROSEMBERG L.A.: MRI features of the anterolateral ligament of the knee. Skelet. Radiol., 44 (3): 403-10, 2015.

17-CLAES S., BARTHOLOMEEUSEN S. and BELLEMANS J.: High prevalence of anterolateral ligament abnormalities in magnetic resonance images of anterior cruciate ligament-injured knees. Acta Orthop. Belg., 80: 45-9, 2014.

18- STIJAK L., BUMBASIREVIC' M., RADONJIC' V., et al.: Anatomic description of the anterolateral ligament of the knee. Knee Surg. Sports Traumatol. Arthrosc., Doi: https:// . doi.org/10.1007/s00167-014-3422-6, 2014.

19- CATERINE S., LITCHFIELD R., JOHNSON M., CHRONIK B. and GETGOOD A.: A cadaveric study of the anterolateral ligament: Reintroducing the lateral capsular ligament. Knee Surg. Sports Traumatol. Arthrosc., doi: 10.1007/s00167-014-3117-z, 2014.

20- DODDS A.L., HALEWOOD C., GUPTE C.M., WILLIAMS A. and AMIS A.A.: The anterolateral ligament: Anatomy, length changes and associa-tion with the Segond fractures. Bone Joint J., 96-B: 325-31, 2014.

21- SONNERY-COTTET B., THAUNAT M., FREYCHET B., PUPIM B.H.B., MURPHY C.G. and CLAES S.: Outcome of a combined anterior cruciate ligament and anterolateral ligament reconstruction technique with a minimum 2-year follow-up. Am. J. Sports Med., 43: 1598$605,2015$.

22- MACKAY G.M., BLYTH M.J., ANTHONY I., HOPPER G.P. and RIBBANS W.J.: A review of ligament augmentation with the InternalBraceTM: The surgical principle is described for the lateral ankle ligament and ACL repair in particular, and a comprehensive review of other surgical applications and techniques is presented. Surg. Technol. Int., 26: 239-25537, 2015.

23- HELITO C.P., HELITO P.V., COSTA H.P., et al.: MRI evaluation of the anterolateral ligament of the knee: Assessment in routine 1.5-T scans. Skelet. Radiol., 43: 1421-7, 2014

27- De MAESENEER M., BOULET C., WILLEKENS I., et al.: Segond fracture: Involvement of the iliotibial band, anterolateral ligament, and anterior arm of the biceps femoris in knee trauma. Skeletal Radiol., 44: 413-21, 2015.

25- HELITO C.P., HELITO P.V., COSTA H.P., et al.: Assessment of the Anterolateral Ligament of the Knee by Magnetic Resonance Imaging in Acute Injuries of the Anterior Cruciate Ligament.Arthroscopy: The Journal of Arthroscopic and Related Surgery, Vol. 33, No. 1 (January): pp. 140-6, 2017.

26- PORRINO J. Jr., MALONEY E., RICHARDSON M., MULCAHY H., HA A. and CHEW F.S.: The anterolateral ligament of the knee: MRI appearance, association with the Segond fracture, and historical perspective. A.J.R. Am. J. Roentgenol., 204: 367-73, 2015.

27- CLAES S., LUYCKX T., VEREECKE E. and BELLEMANS J.: The Segond fracture: A bony injury of the anterolateral ligament of the knee. Arthroscopy, 30: 147582, 2014.

28- CHURCHILL D.L., INCAVO S.J., JOHNSON C.C. and BEYNNON B.D.: The transepicondylar axis approximates the optimal flexion axis of the knee. Clin. Orthop. Relat. Res., 356: 111-8, 1998.

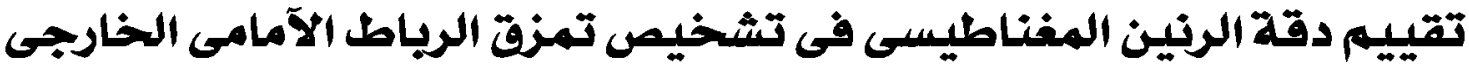 الهصاحب لتهزق الرياط الصليبى الآمامى الحماد الرياد}

$$
\begin{aligned}
& \text { تهدف هذه الدراسة إلى تقييم قدرة الرنين المغناطيسى على تثخيص إصابات الآربطة الآمامية الجانبية فى المرضى الذين يعانون من } \\
& \text { القطع الحاد في الآربطة الصليبية الآمامية. } \\
& \text { تمت الدراسة بآثر رجعى على ستة وتسعين مريضـاً ممن تم عمل رنين مغناطيسى للركبة لهم فى غضسون شهرين بعد إصابتهم ثم تم عمل } \\
& \text { إصلاح للرياط الصليبى الآمامى لهم. }
\end{aligned}
$$

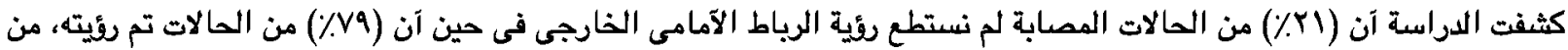

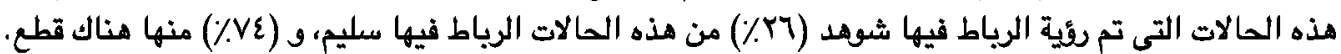

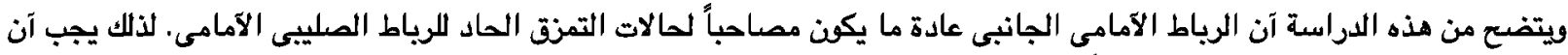

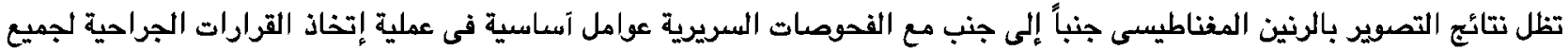

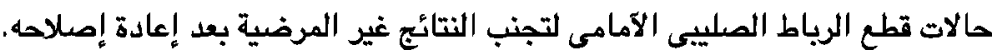

